\title{
Correlation Self-Compassion and Happiness among University Students in Timor-Leste: Gratitude as Moderation Variable
}

\author{
Lurdes Antonina Dos Santos Beni ${ }^{1} \&$ Latipun $^{1}$ \\ ${ }^{1}$ University of Muhammadiyah Malang, Indonesia \\ Correspondence: Latipun, Psychology Faculty, University of Muhammadiyah Malang, Jl. Tlogomas 246 Malang, \\ Indonesia. E-mail: latipun@umm.ac.id
}

Received: February 12, 2019

Accepted: March 3, 2019

Online Published: March 11, 2019

doi:10.5539/ijps.v11n2p1

URL: https://doi.org/10.5539/ijps.v11n2p1

\begin{abstract}
Happiness is important for humans because happiness experienced by each is closely related to high self-compassion. Individuals who have a high understanding of the events they experience tend to feel happy. The relationship can be strengthened by gratitude. The purpose of this study was to find out the relationship between Self-compassion and happiness moderated by gratitude to students. The subject in this study was 316 students. Instrument research uses the Self-compassion Scale (SCS), The Oxford Happiness Questionnaire (OHQ) and the Gratitude Questionnaire (GQ). The analysis of the data used the Moderated Regression Analysis (MRA). The results showed that there was a positive and significant relationship between self-compassion and happiness which was moderated by gratitude $(\beta=.29$ and $\mathrm{p}=.046)$, and self-compassion contribution with happiness was moderated by gratitude which was equal to $18.1 \%$.
\end{abstract}

Keywords: self-compassion, happiness, gratitude, student

\section{Introduction}

Every individual wants to be happy. Happiness is the biggest goal that every human being wants to achieve (Vitrano, 2010). The individual obtains happiness through fulfilling his needs, accepting all his or her shortcomings and adapting to his environment and social expectations (Sariçam, 2015). The activities of each are a manifestation of his desire to gain happiness.

Happiness is subjective that the individual experiences it depends on his perception. Individuals can feel happy even though they experience bad difficulties and living conditions, but other individuals may find themselves unhappy even though they live in better conditions (Qayoom \& Husain, 2016). Happiness is an individual's life experience characterized by positive feelings such as feeling happy and experiencing satisfaction with his life (Veenhoven, 2012).

Wood, Froh, and Geraghty (2010) states that individuals have a different way of achieving happiness. According to Wood et al., some individuals view personal freedom and social welfare as the factors that most influence their happiness. Individuals who have freedom can maintain their desires so they can increase happiness in their lives. However, other individuals live by refusing to get happiness in that way; they reject wealth, life partners, or freedom. They feel happier with simplicity in their lives and focus on life goals and create positive values and are meaningful for their daily lives.

\subsection{Self-Compassion and Happiness}

Self-compassion is a source of happiness and psychological well-being. Self-compassion is a process of understanding individuals against various difficulties or failures, without criticizing or judging themselves. With self-compassion, individual see all events experienced as life processes that must be lived (Neff \& McGehee, 2010). Barnard \& Curry's (2011) study found that individuals who have high self-compassion tend to have good psychological happiness and well-being. According to Neff (2011), self-compassion positively correlated with life satisfaction, happiness, optimism, and hope, on the contrary, self-compassion correlates negatively with depression and anxiety.

Self-compassion is a positive element of personality. Individuals with high self-compassion are predicted to be able to deal with a variety of unfortunate events that they experience, pressure-filled situations, having a love for themselves, not blaming themselves. Self-compassion can increase an individual's awareness of himself that his 
life is not an easy thing; success and happiness start from failure (Zessin, Dickhäuser, \& Garbade, 2015).

According to Ferguson, Kowalski, Mack, \& Sabiston (2015), individuals with high self-compassion have comfort in their lives and feel happy even in stressful situations. Thus, self-compassion is an essential factor of psychological well-being and is useful for promoting individual mental health (Campos et al., 2016; Iskender \& Akin, 2011; Barnard \& Curry, 2011).

Self-compassion is a source of eudemonic happiness. Eudaemonia happiness involves a person on purpose and meaning in everyday life (Lopes, da Palma, Garcia, \& Gomes, 2016). Individuals with high self-compassion do not avoid suffering or failure that they experience but interpret it well to produce well-being rooted in experience.

The results of the research of Zessin et al. (2015) stated that students who have high self-compassion could positively understand all their shortcomings and inability and consider that the conditions they experience are life processes experienced. The research conducted by Ahmet (2010) states that individuals who have high self-compassion can understand all their shortcomings and have an understanding of the events they experience.

The function of self-compassion is to reduce negative emotions such as anxiety, criticize and isolate oneself and increase positive emotions such as a positive mindset, have high expectations and are optimistic in facing various difficulties in his life so that he can establish good relations with his social environment (Homan, 2016). Self-compassion provides understanding and protects individuals against rumination, depression, and anxiety (Neff, Kirkpatrick, \& Rude, 2007). Self-compassion fosters well-being by helping individuals feel cared for, connected with the social environment and emotionally calm to increase happiness in everyday life (Akin, 2010). Based on the results of various studies it can be hypothesized that self-compassion is related to individual happiness.

\subsection{Gratitude and Happiness}

In general, gratitude conceptualized as both disposition and state or emotion. Gratitude is eternal gratitude that continues throughout the situation and over time (Chen, $\mathrm{Wu}, \& \mathrm{Chen}, 2015)$. Initially, gratitude defined as the general tendency to recognize and respond emotionally to the virtue the others and positive results obtained by someone. Then Lin (2015) notes the broader concept of gratitude as emotions, attitudes, moral virtues, habits and personality traits. So gratitude forms a positive attitude or emotion for a variety of unpleasant life experiences such as failures, shortcomings, and events experienced so that individuals who are always grateful for life experiences that are full of stress can increase happy feelings (Kong, Ding, \& Zhao, 2015).

Gratitude is forming positive emotions in the form of gratitude for what owned and for the events that they experience. Gratitude correlates with various components of happiness. Individuals with more gratitude tend to think positively about various aspects of their lives. Individuals with more gratitude experience well-being and have strong expectations in facing the events (Davis et al., 2016).

Gratitude is a form of positive emotion that contrasts to negative emotions such as anxiety, jealousy, and anger. Gratitude can change individuals to become better and have a positive mindset so they can establish relationships with others and create harmony with their surrounding environment.

\subsection{Gratitude as a Moderating Variable}

Gratitude is the strength of character that is consistently and strongly related to happiness and well-being (Wood et al., 2010). Grateful individuals can experience feelings that are happier than those who are less grateful.

Gratitude conceptually linked as strengths of pro-social character (such as empathy), psychological and physical health (Breen, Kashdan, Lenser \& Fincham, 2010). The research by Arya \& Khandelwal (2014) shows that psychological interventions can enhance gratitude and happiness and both contribute positively to one's well-being. Fostering gratitude seems to provide various benefits in several domains, including the domains of mental health, physical health, and social welfare (Lambert, Graham, \& Fincham, 2009). Feelings of gratitude strengthen social relations and help people overcome stressful situations (Aricioglu, 2016).

Research on self-compassion states that people who have high self-compassion will feel happy with their lives (Neff, 2011). Not only self-compassion that increases happiness in every individual but gratitude can also increase happiness. People who are always grateful can form positive emotions and mindsets and can understand all the events they experience so they can increase happiness (Wood et al., 2010).

Gratitude is one aspect of positive emotions that encourages individuals always to have a sense of accepting and thanking for what they have (Saricaoglu \& Arslan, 2013). In general, gratitude as both a disposition and a state or emotion. As a disposition, gratitude is seen as a characteristic of eternal gratitude that continues throughout the situation and over time (Kong et al., 2015). Grateful individuals experience and express gratitude in responding to 
benefits or gifts from others. As a situation, the occurrence of gratitude usually related to the perception of receiving improper personal benefits because of the good intentions of others (Simão \& Seibt, 2014).

Previous research has found that happiness has a significant relationship with gratitude. Some previous studies have shown that gratitude contributes to psychological health and well-being and happiness and reduces negative emotions. Happy people tend to be more energetic, passionate and passionate than less happy individuals, and happiness associated with increased activity and increasing positive emotions (Kirmani, 2015).

Individuals who have high gratitude can also increase happiness because gratitude can strengthen the relationship of self-compassion with happiness. Therefore it can be said that gratitude can increase self-compassion with godliness because individuals who are always grateful can shape the personality of a person who can understand and accept all events positively so that they can improve well-being and happiness (Neff, 2011).

\section{Hypothesis}

The hypothesis in this research are:

1. There is a positive correlation between self-compassion and happiness

2. Gratitude variable moderates the relationship self-compassion and happiness.

\section{Methods}

\subsection{Subject}

The subjects who participated in this research were students of the Public Health Faculty of the University of Da Paz (UNPAZ) Dili, Timor-Leste, which consisted of 116 third semester students (36.7\%) 200 fourth semester students $(63.3 \%)$. They were $19-21$ years old $(M=20.40, S D=3.02)$, most of them were women $(75 \%)$. Table 1 indicates the characteristics of subject research.

Table 1. Description of Subjects $(\mathrm{N}=316)$

\begin{tabular}{lll}
\hline Characteristics & $\boldsymbol{N}$ & (\%) \\
\hline Semester & & \\
$\quad$ Semester III & 116 & 36.7 \\
$\quad$ Semester IV & 200 & 63.3 \\
Age & & \\
$19-21$ & 208 & 65.8 \\
$22-25$ & 108 & 34.2 \\
Gender & & \\
$\quad$ Female & 237 & 75 \\
$\quad$ Male & 79 & 25 \\
\hline
\end{tabular}

\subsection{Instrument}

Self-compassion scale (SCS; Neff, 2003) is an instrument for measuring variable self-compassion. SCS consists of three components, namely self-kindness $\mathrm{v}$ self-judgment (10 items), common- humanity vs. isolation ( 8 items), mindfulness $\mathrm{v}$ sover identification ( 8 items). SCS is arranged in a Likert scale format with five alternative answers, starting from very agree (SS) to disagree (STS) strongly. Example item: "When I think about my inadequacies, it tends to make me feel more separate and cut off from the rest of the world." The higher the value obtained means the higher the self-compassion that the subject has. Research at Dili University, SCS obtained consistent internal coefficients as large as Cronbach's $\alpha=.85$.

The Oxford Happiness Questionnaire (OHQ; Hills \& Argyle, 2002) is an instrument for measuring happiness variables. OHQ consists of 29 items made in a Likert Scale format with five alternative answers, starting from very agree (score 5) to strongly disagree (score 1). Example item: "I am intensely interested in other people." The higher the value obtained means the higher the happiness of the individual. OHQ obtained an internal conductivity coefficient of Cronbach's $\alpha=.82$.

Gratitude Questionnaire (GQ) is an instrument for measuring gratitude (McCullough, Emmons \& Tsang, 2002). GQ consists of 6 items arranged in a Likert scale format with five alternative answers, starting from strongly agree (score 5) to strongly disagree (score 1). Example item: "As I get older I find myself more able to appreciate the people, events, and situations that have been part of my life history." GQ obtained an internal consistency index of 
Alpha Cronbach's 0.80 (Loo, Tsai, Raylu, \& Oei, 2014), and the results of testing at Universidade Dili obtained an internal consistency coefficient of Alpha Cronbach's $\alpha=.87$.

\subsection{Data Analysis}

The research data were analyzed through the Moderated Regression Analysis (MRA) technique which aims to determine the role of gratitude in moderating the relationship between self-compassion and happiness.

\section{Results}

\subsection{Description of Research Variables}

Descriptive data analysis showed that the subject's self-compassion obtained a value of $\mathrm{M}=3.38, \mathrm{SD}=.27$; gratitude value is $\mathrm{M}=3.55, \mathrm{SD}=.46$; and happiness gets a value of $\mathrm{M}=3.64, \mathrm{SD}=.35$. The results of the correlation test between variables indicate that when the variable has a positive relationship. Table 2 is a description of the result of the correlation test.

Table 2. Mean, Standard Deviation and Variable Intercorrelation $(\mathrm{N}=316)$

\begin{tabular}{llllll}
\hline Variable & Mean & SD & 1 & 2 & 3 \\
\hline 1. Self-compassion & 3.38 & .27 & 1 & & \\
2. Gratitude & 3.55 & .46 & $.25^{*}$ & 1 & \\
3. Happiness & 3.64 & .35 & $.26^{*}$ & $.37^{*}$ & 1 \\
\hline
\end{tabular}

Note: $* \mathrm{p}<0.05$

\subsection{Contribution Gratitude and Self-Compassion to Happiness}

Based on the regression test, we have known that self-compassion and gratitude contribute to happiness, $7 \%$, and $17 \%$, respectively. By including gratitude as a moderator variable, the contribution of self-compassion to happiness is predicted to be $18 \%$. The results of the analysis show that gratitude as a moderator variable can predict the relationship of self-compassion with happiness (Table 3).

Table 3. Results of Regression Analysis

\begin{tabular}{llll}
\hline Variable & $\boldsymbol{B}$ & $\boldsymbol{R}^{2}$ & $\boldsymbol{p}$ \\
\cline { 2 - 4 } Self-compassion & .23 & .07 & .000 \\
Gratitude & .26 & .17 & .000 \\
Self-compassion x Gratutude & .29 & .18 & .04 \\
\hline
\end{tabular}

Note: ${ }^{*} \mathrm{p}<0.05$

\subsection{Gratitude as a Moderator Variable}

The results of statistical analysis showed that there was a positive relationship between self-compassion and happiness $(\beta=.23, \mathrm{p}=.000)$ and gratitude had a positive relationship with happiness $(\beta=26, \mathrm{p}=.00)$. The relationship between self-compassion and happiness became stronger after an analysis that included gratitude as a moderator variable $(\beta=.29 ; \mathrm{p}=.04)$ (see Table 3$)$. Thus, the hypothesis that states gratitude as a moderator variable can moderate the relationship of self-compassion with happiness, and gratitude can strengthen the relationship of self-compassion with happiness received. 


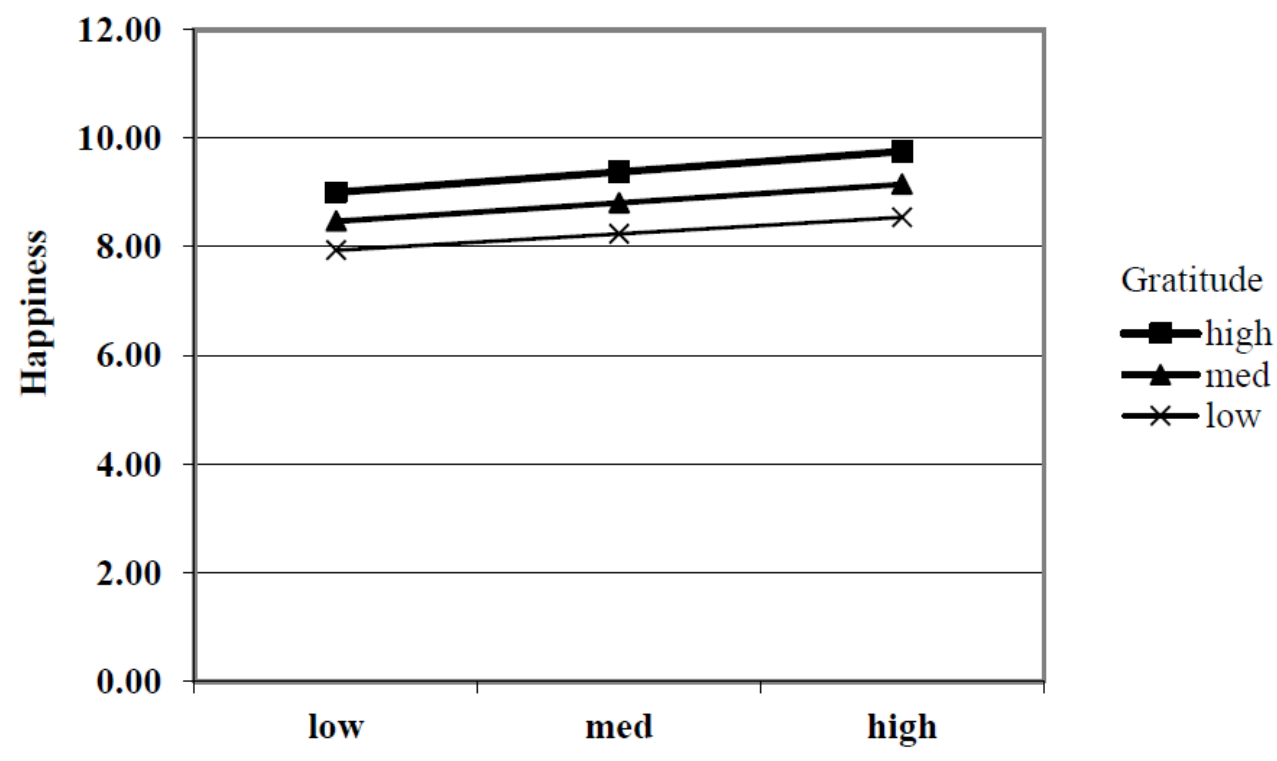

\section{Self -compassion}

Figure 1. Relations between Variables

Figure 1 illustrates the effect of gratitude as a moderator variable on the relationship between self-compassion and happiness, the higher the gratitude, the stronger the relationship between self-compassion and happiness. The higher the gratitude of the subject can form the personality of individuals who accept and understand all events positively so that it can increase happiness, meaning that the gratitude variable can be a moderating variable of the relationship between self-compassion happiness.

\section{Discussion}

The purpose of the study was to determine the relationship between self-compassion and happiness moderated by gratitude to students. The results showed that there was a positive and very significant relationship between self-compassion and happiness; meaning that the better the self-compassion, the higher the happiness possession will be, and vice versa. The results of the research are in line with the findings of Hollis-Walker \& Colosimo (2011) that individuals who have high self-compassion can feel comfortable in their environment and do not criticize themselves when facing various difficult situations and can respond to all events well so they can increase happiness in individuals.

Individuals who have high self-compassion can increase their happiness because self-compassion is a vital source of psychological well-being, physical, mental, and social well-being. Therefore, individuals who have high self-compassion can understand, realize and accept all deficiencies in themselves and can comprehend all events positively so that they can increase happiness which is happiness that originates in their selves.

The results showed that gratitude was able to moderate the relationship between self-compassion and happiness, meaning that the higher the gratitude, the stronger the relationship between self-compassion and happiness. This finding is consistent with the result of research by Rajan \& Easvaradoss (2012) that students with higher gratitude tend to higher happiness. The individuals with higher gratitude tend to think positively toward their experience both positive and negative experiences, and they can respond positively to various their problems and experience. Therefore, individuals need positive thoughts and accept deficiencies in themselves and assume problems faced are part of the life that be lived by everyone.

Students who are grateful in their lives do not easily complain about every problem they experience, think positively and take lessons from the events or problems they face. Therefore it can be said that gratitude plays a vital role in increasing happiness because individuals who have high gratitude can have positive thought patterns and emotions in the events they experience both positive events and adverse events and thank or thankful for what others give and what he has.

According to Sativa \& Helmi (2013) states that individual with gratitude can experiemce happiness which is happiness that comes from within their selves. When individuals have high gratitude, they can have high hopes and 
are optimistic in living their lives compared to individuals who have no gratitude. Besides gratitude gives positive emotions and has a positive mindset so that they can understand and understand what they have. Because true happiness lies in what we are grateful for and what we have.

Happiness in the perspective of Eastern culture is different from happiness in the perspective of western culture. Happiness in western culture is more hedonic happiness where happiness is only obtained through pleasure and enjoyment while happiness in the perspective of Eastern culture is more eudemonic happiness where happiness is obtained through high gratitude, creating positive values and involving individuals in their goals and meanings in their daily lives.

Gratitude plays an important role contributing to the relationship of self-compassion with happiness, but gratitude has a small contribution to the relationship of self-compassion to happiness even though the moderator variable can strengthen the relationship of self-compassion with happiness. Therefore it can be said that most likely other factors can influence happiness and not just gratitude as a moderator variable but another independent variable. In line with the research of Mary \& Patra (2015) that gratitude with the heart will make someone feel the existence of God in him, and always thank you for what he has so that it can increase happiness. Gratitude has an essential role in shaping behavior, emotions and positive thinking patterns for each as well as students.

Individuals have high gratitude, individuals can also have high happiness, be optimistic and have high expectations in their lives, because happiness that actually comes from ourselves is grateful for what they have and do not complain about what happens in our lives because happiness that actually starts with what we are grateful for and what we have. Thus it can be concluded that individuals who have high gratitude can feel happiness in their lives because gratitude can strengthen the relationship of self-compassion with happiness.

\section{Conclusion}

The results of the study show that there is a positive relationship between self-compassion and happiness. The result of research means that the higher the self-compassion, the higher the happiness in the individual. Gratitude can strengthen the relationship of self-compassion with happiness. Therefore individuals who have high gratitude can improve the relationship of self-compassion with happiness. Happiness is essential for every human being, especially for each, individual happiness can be obtained through self-compassion with gratitude because individuals who have high gratitude can form the personality of individuals who can understand and accept all events positively. The implication of the recent research that gratitude is a factor to consider in improve happiness for students include in providing counseling and therapy as part of student services. Future research we recommend the gratitude as variable to predict performance, social relation, and emotional stability.

\section{Acknowledgments}

The authors want to thank Djudiyah for her valuable contributions in the check the manuscript. I would also like to thank the academic staff of Public Health Faculty, the University of Da Paz (UNPAZ) Dili, Timor-Leste, for their assistance in the data collection process.

\section{References}

Aricioglu, A. (2016). Mediating the effect of gratitude in the relationship between forgiveness and life satisfaction among university students. International Journal of Higher Education, 5(2), 275-282. https://doi.org/10.5430/ijhe.v5n2p275

Akin, A. (2010). Self-compassion and loneliness. International Online Journal of Educational Sciences, 2(3), 702-718.

Arya, B., \& Khandelwal, S. (2014). Inculcating gratitude: an experimental investigation of gratitude and subjective happiness in daily life. Indian Journal of Positive Psychology, 5(4), 474-476.

Barnard, L. K. \& Curry, J. F. (2011). The relationship of clergy burnout to self-compassion and other personality dimensions. Pastoral Psychology, 61(2), 149-163. http://dx.doi.org/10.1007/s11089-011-0377-0

Breen, W. E., Kashdan, T. B., Lenser, M. L. \& Fincham, F. D. ( 2010 ) Gratitude and forgiveness: Convergence and divergence on self-report and informant ratings. Personality and Individual Differences, 49, 932-937. http://dx.doi.org/10.1016/j.paid.2010.07.033

Campos, D., Cebolla, A., Quero, S., Bretón-López, J., Botella, C., Soler, J., ... Baños, R. M. (2016). Meditation and happiness: Mindfulness and self-compassion may mediate the meditation-happiness relationship. Personality and Individual Differences, 93, 80-85. http://dx.doi.org/10.1016/j.paid.2015.08.040.

Chen, L. H., Wu, C. H., \& Chen, S. (2015). Gratitude and athletes' life satisfaction: A intra-individual analysis on 
the moderation of ambivalence over emotional expression. Social Indicators Research, 123(1), 227-239. http://dx.doi.org/10.1007/s11205-014-0737-0

Davis, D. E., Choe, E., Meyers, J., Wade, N., Varjas, K., Gifford, A., ... Worthington, E. L. (2016). Thankful for the little things: A meta-analysis of gratitude interventions. Journal of Counseling Psychology, 63(1), 20-31. https://doi.org/10.1037/cou0000107.

Ferguson, L. J., Kowalski, K. C., Mack, D. E., \& Sabiston, C. M. (2015). Self-compassion and eudaimonic well-being during emotionally difficult times in Sport. Journal of Happiness Studies, 16(5), 1263-1280. https://doi.org/10.1007/s10902-014-9558-8.

Hollis-Walker, L., \& Colosimo, K. (2011). Mindfulness, self-compassion, and happiness in non-meditators: A theoretical and empirical examination. Personality and Individual Differences, 50(2), 222-227. http://dx.doi.org/10.1016/j.paid.2010.09.033.

Hills, P. \& Argyle, M. (2002). The Oxford Happiness Questionnaire: A compact scale for the measurement of psychological well-being. Personality and Individual Differences, 33, 1073-1082. https://doi.org/10.1016/S0191-8869(01)00213-6.

Homan, K. J. (2016). Self-compassion and psychological well-being in older adults. Journal of Adult Development, 23(2), 111-119. https://doi.org/10.1007/s10804-016-9227-8

Iskender, M., \& Akin, A. (2011). Self-compassion and internet addiction. Turkish Online Journal of Educational Technology, 10(3), 215-221.

Kirmani, M. N. (2015). Gratitude, forgiveness and subjective well-being among college going students. International Journal of Public Mental Health and Neurosciences, 2(2), 1-10.

Kong, F., Ding, K., \& Zhao, J. (2015). The relationships among gratitude, self-esteem, social support and life satisfaction among undergraduate students. Journal of Happiness Studies, 16(2), 477-489. https://doi.org/10.1007/s10902-014-9519-2

Lambert, N. L., Graham, S., \& Fincham, F. D. (2009). A prototype analysis of gratitude: Varieties of gratitude experiences. Personality and Social Psychology Bulletin, 35, 1193-1207. https://doi.org/10.1177/0146167209338071.

Lin, C.-C. (2015). Impact of gratitude on resource development and emotional well-being. Social Behavior and Personality, 43(3), 493-504. https://doi.org/10.2224/sbp.2015.43.3.493.

Loo, J. M. Y., Tsai, J., Raylu, N., \& Oei, T. P. S. (2014). Gratitude, hope, mindfulness and personal growth initiative: Buffers or risk factors for problem gambling? PLOS ONE, 9(2), 1-11. https://doi.org/10.1371/journal.pone.0083889.

Lopes, M. P., da Palma, P. J., Garcia, B. C., \& Gomes, C. (2016). Training for happiness: the impacts of different positive exercises on hedonism and eudaemonia. SpringerPlus, 5(1), 7-44. https://doi.org/10.1186/s40064-016-2407-y

Mary, E. M., \& Patra, S. (2015). Relationship between forgiveness, gratitude and resilience among the adolescents. Indian Journal of Positive Psychology, 6(1), 63-68

McCullough, M. E., Emmons, R. A., \& Tsang, J. A. (2002). The grateful disposition: A conceptual and empirical

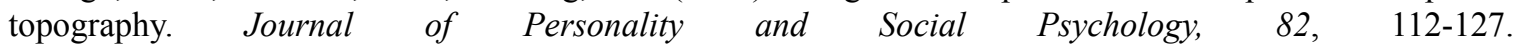
http://dx.doi.org/10.1037/0022-3514.82.1.112

Neff, K. D. (2003). Development and validation of a scale to measure self-compassion. Self Identity, 2, 223-250. https://doi.org/10.1080/15298860309027

Neff, K. D. (2011). Self-compassion, self-esteem, and well-being. Social and Personality Psychology Compass, 5(1), 1-12. http://dx.doi.org/10.1111/j.1751-9004.2010.00330.x

Neff, K. D., Kirkpatrick, K. L., \& Rude, S. S. (2007). Self-compassion and adaptive psychological functioning. Journal of Research in Personality, 41, 139-154. https://doi.org/10.1016/j.jrp.2006.03.004

Neff, K. D., \& McGehee, P. (2010). Self-compassion and psychological resilience among adolescents and young adults. Self and Identity, 9(3), 225-240. https://doi.org/10.1080/15298860902979307

Qayoom, S. \& Husain, A. (2016). Happiness and well-being. Indian Journal of Health and Wellbeing, 7(4), 461-464

Rajan, R., \& Easvaradoss, V. (2012). The effect of happiness related psychological intervention on happiness, 
forgiveness and gratitude among adolescents. Indian Journal of Positive Psychology, 3(4), 402-405.

Sariçam, H. (2015). Subjective happiness and hope. Universitas Psychologica, 14(2), 685-694. http://dx.doi.org/10.11144/Javeriana.upsy14-1.shah

Saricaoglu, H., \& Arslan, C. (2013). An investigation into psychological well-being levels. of higher education students with respect to personality. Educational Sciences, 13(4), 2097-2105. https://doi.org/10.12738/estp.2013.4.1740

Sativa, A. R., \& Helmi, A. F. (2013). Syukur dan harga diri dengan kebahagiaan remaja. Jurnal Psikologi, 5(10), $1-12$.

Simão, C., \& Seibt, B. (2014). Gratitude depends on the relational model of communal sharing. PLoS ONE, 9(1), 115-120. https://doi.org/10.1371/journal.pone.0086158

Veenhoven, R. (2012). Happiness : Also known as "life-satisfaction" and "subjective well-being." Handbook of Social Indicators and Quality of Life Research, (3), 63-77. https://doi.org/10.1007/978-94-007-2421-1

Vitrano, C. (2010). The subjectivity of happiness. Journal of Value Inquiry, 44(1), 47-54. https://doi.org/10.1007/s10790-010-9208-2

Wood, A. M., Froh, J. J., \& Geraghty, A. W. A. (2010). Gratitude and well-being: A review and theoretical integration. Clinical Psychology Review, 30(7), 890-905. https://doi.org/10.1016/j.cpr.2010.03.005

Zessin, U., Dickhäuser, O., \& Garbade, S. (2015). The relationship between self-compassion and well-being: A meta-analysis. Applied Psychology: Health and Well-Being, 7(3), 340-364. https://doi.org/10.1111/aphw.12051

\section{Copyrights}

Copyright for this article is retained by the author(s), with first publication rights granted to the journal.

This is an open-access article distributed under the terms and conditions of the Creative Commons Attribution license (http://creativecommons.org/licenses/by/4.0/). 